\title{
Rare Cause of Cholestasis: Caroli's Syndrome
}

\author{
(D) Didem Gülcü Taşkın, ${ }^{1}$ (D) Ayşe Selcan Koç, ${ }^{2}$ (D) Sibel Yavuz, ${ }^{3}$ (D) Sinan Sözütok, ${ }^{4}$ \\ (D) Elife Aşut, ${ }^{5}$ (D) Gökhan Tümgör ${ }^{3}$
}

\author{
'Department of Pediatric Gastroenterology, Adana City Training and Research Hospital, \\ Adana, Turkey \\ 2Department of Radiology, Adana City Training and Research Hospital, Adana, Turkey \\ ${ }^{3}$ Department of Pediatric Gastroenterology, Cukurova Faculty of Medicine, Adana, Turkey \\ ${ }^{4}$ Department of Interventional Radiology, Adana City Training and Research Hospital, \\ Adana, Turkey \\ ${ }^{5}$ Department of Pathology, Adana City Training and Research Hospital, Adana, Turkey
}

\section{ABSTRACT}

Caroli disease is a rare congenital disease characterized by multiple segmental cystic, saccular dilatations of the intrahepatic biliary tract. We diagnosed Caroli's syndrome in our patient who applied with cholangitis attack with the 'Central Dot Sign' finding in abdominal computed tomography, which is a characteristic finding for Caroli's Syndrome; we wanted to emphasize the value of radiological data in diagnosis. As it is a rare syndrome, it should be considered during the differential diagnosis of cholestasis. An 18-month-old girl was admitted to our hospital because of her jaundice that had not improved for a month. The patient had hypertransaminasemia and direct hyperbilirubinemia, because of the high markers of infection, antibiotherapy was started by considering cholangitis. In abdominal ultrasonography, liver parenchyma was interpreted as having multiple cystic lesions and dilatation in intrahepatic bile ducts. The patient's abdominal computed tomography had saccular, fusiform dilatations of the intrahepatic bile ducts in both liver lobes. 'Central Dot Sign' finding was observed in intrahepatic bile ducts. Portal, periportal fibrosis and bile duct proliferation, bridging, nodule formation were present in the patient's liver biopsy. In our patient who was investigated for neonatal cholestasis, we diagnosed Caroli's syndrome on the presence of the 'Central Dot Sign', a characteristic finding in computed tomography. The early diagnosis of this very rare disease affects the prognosis after liver transplantation. Caroli's syndrome should be considered in the differential diagnosis in every patient presenting with cholestasis, especially in the presence of recurrent cholangitis attacks.

Address for correspondence: Dr. Didem Gülcü Taşkın. Department of Pediatric Gastroenterology, Adana City Training and Research Hospital, Adana, Turkey

Phone: +905059269432

E-mail:dgulcu@gmail.com

Received Date: 09.05 .2020

Accepted Date: 05.06.2020

Published online: 10.03.2021

OCopyright 2021 by Anatolian Journal of Family Medicine -

Available online at www.anatoljfm.org

OPEN ACCESS

Keywords: Caroli's Syndrome, cholestasis, cholangitis, hyperbilirubinemia, liver fibrosis, portal hypertension

\section{INTRODUCTION}

Caroli Disease $(C D)$ is a rare congenital disease characterized by multiple segmental cystic or saccular dilatations of the intrahepatic biliary tract. ${ }^{[1]}$ The frequency in a population is $1 / 1.000 .000 .{ }^{[2]}$ There are two types, CD and Caroli's syndrome (CS). In CS, congenital hepatic fibrosis is observed together with cystic dilatations of intrahepatic bile ducts. Over $80 \%$ of CD is diagnosed before age $30 .{ }^{[3]}$ In CS, the diagnosis is often made in the first 10 years of age, with patients often presenting with recurrent attacks of cholangitis. Portal hypertension, liver fibrosis and cirrhosis develop in the later stages of the disease ${ }^{[4]} \mathrm{Here}$, with this case report we want to present our patient who applied with cholangitis attack and diagnosed with Caroli's Syndrome. 


\section{CASE REPORT}

An 18-month-old girl presented to our clinic with the complaint of jaundice, fever and abdominal distention. It was learned that the patient had jaundice for a month and that the complaint of fever and abdominal swelling was added for a week. On physical examination, the patient was icteric and abdominal examination revealed hepatosplenomegaly. Body temperature was $38.5^{\circ} \mathrm{C}$, blood pressure arterial was $90 / 50 \mathrm{mmHg}$, pulse was $120 / \mathrm{min}$. Patients weight was $6000 \mathrm{~g}(<3 \mathrm{p})$ and height was $70 \mathrm{~cm}(<3 \mathrm{p})$. Laboratory tests related to cholestasis at the time of application and followup of the patient are shown in Table 1.

The patient was hospitalized with the diagnosis of cholangitis due to fever, jaundice, direct hyperbilirubinemia and high level of acute phase reactants, and third generation cephalosporins (100 mg/kg/day, divided three dose, intravenous) and metronidazole (30 mg/day, divided three doses, intravenous) antibiotherapy was initiated.

The patient's blood lipid profile and thyroid function tests, alpha-fetoprotein, CA19-9, alpha-1 antitrypsin values were normal. Biotinidase activity, urine, blood amino acid profile, urine organic acid level, carnitine profile and acid phosphatase value were normal. Serologies of hepatitis $A$, hepatitis B, hepatitis C, HIV and Toxoplasma, Rubella, Cyto- megalovirus, Herpes virus, syphilis test results were negative. Multiple cystic lesions of the parenchyma in heterogeneous appearance and varying sizes were detected on the abdominal and portal Doppler ultrasound of the patient (Fig. 1). Paraumbilical, perisplenic, portosystemic collateral vascular formations were observed.

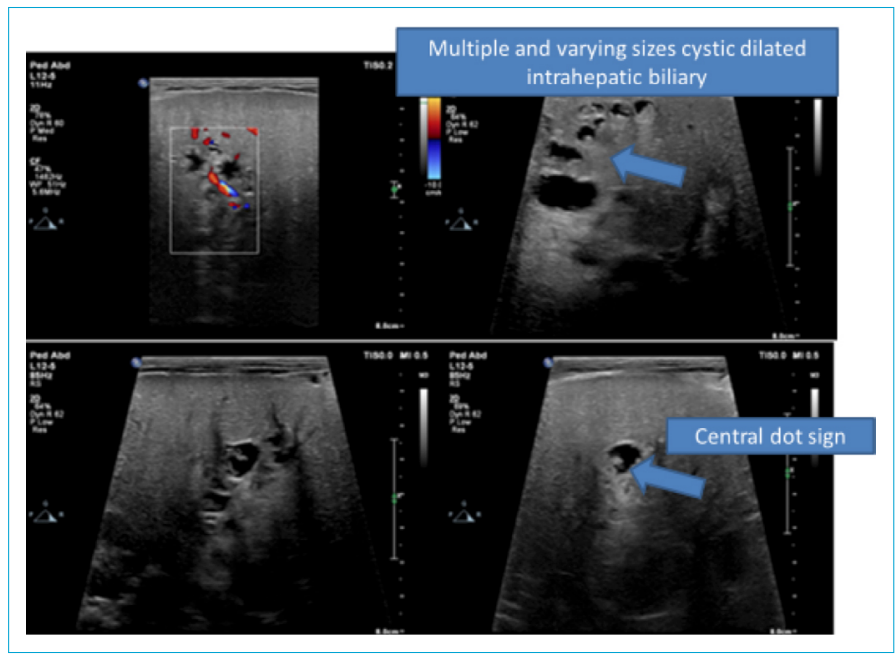

Figure 1. Abdominal ultrasonography.

Liver parenchymal heterogeneity and multiple cystic spaces of varying sizes, communicating with dilated intrahepatic biliary radicles. Some of the cystic or saccular spaces showed irregular echogenic linear strands through them known as 'Central Dot Sign'.

Table 1. Laboratory findings at the time of admission versus follow-ups

\begin{tabular}{lcccc} 
& Reference values & $\mathbf{1}^{\text {th }}$ visit & $\mathbf{1}^{\text {th }}$ week & 1 $^{\text {th }}$ month \\
\hline AST $(\mu / \mathrm{L})$ & $5.0-35.0$ & 432.0 & 308.0 & 385.0 \\
ALT $(\mu / \mathrm{L})$ & $5.0-35.0$ & 290.0 & 250.0 & 201.0 \\
GGT $(\mu / \mathrm{L})$ & $5.0-38.0$ & 156.0 & 150.0 & 301.0 \\
ALP $(\mu / \mathrm{L})$ & $30.0-120.0$ & 446.0 & 450.0 & 444.0 \\
Total bilirubin $(\mathrm{mg} / \mathrm{dl})$ & $0.3-1.2$ & 8.9 & 10.3 & 13.4 \\
Direct bilirubin $(\mathrm{mg} / \mathrm{dl})$ & $0.0-0.2$ & 5.2 & 6.0 & 7.4 \\
PT $(\mathrm{s})$ & $10.5-14.5$ & 16.0 & 16.0 & 15.3 \\
INR & $0.8-1.2$ & 1.33 & 1.33 & 1.27 \\
Urea $(\mathrm{mg} / \mathrm{dl})$ & $17.0-43.0$ & 12.0 & 15.0 & 18.0 \\
Creatinine $(\mathrm{mg} / \mathrm{dl})$ & $0.5-0.9$ & 0.1 & 0.15 & 0.15 \\
Creatine kinase $(\mu / \mathrm{L})$ & $5.0-145.0$ & 57.0 & 47.0 & 50.0 \\
CRP $(\mathrm{mg} / \mathrm{dl})$ & $0.0-0.8$ & 15.0 & 12.0 & 3.0 \\
Leukocyte $\left(10^{3} / \mu \mathrm{L}\right)$ & $4.8-13.1$ & 18.6 & 10.0 & 18.0 \\
Thrombocyte $\left(10^{3} / \mu \mathrm{L}\right)$ & $189.0-394.0$ & 267.0 & 234.0 & 250.0 \\
Hemogram $(\mathrm{g} / \mathrm{dl})$ & $10.8-14.6$ & 10.7 & 7.8 & 10.9 \\
Fibrinogen $(\mathrm{mg} / \mathrm{dl})$ & $180.0-350.0$ & 227.0 & - & - \\
Albumin $(\mathrm{g} / \mathrm{dl})$ & $3.5-5.2$ & 1.45 & 2.15 & 3.5 \\
\hline ALP: Alkaline Phosphatase; ALT: Alanin Aminotransferaz; AST: Aspartat Aminotransferaz; CRP: C-Reactive \\
Protein; GGT: Gamma-glutamyl Transferase, INR: International & & & \\
\hline
\end{tabular}


The patient's dynamic contrast-enhanced abdominal computed tomography had saccular and fusiform dilatations of the intrahepatic bile ducts in both liver lobes. 'Central Dot Sign' finding was observed in the intrahepatic bile ducts (Fig. 2). ${ }^{[5]}$ Increased parenchymal echogenicity of the liver and saccular dilatations in both liver in the patient's magnetic resonance cholangiopancreatography (Fig. 3). In the patients' liver biopsy, periportal fibrosis, bile duct proliferation, bridging and nodule formation were observed (Fig. 4).

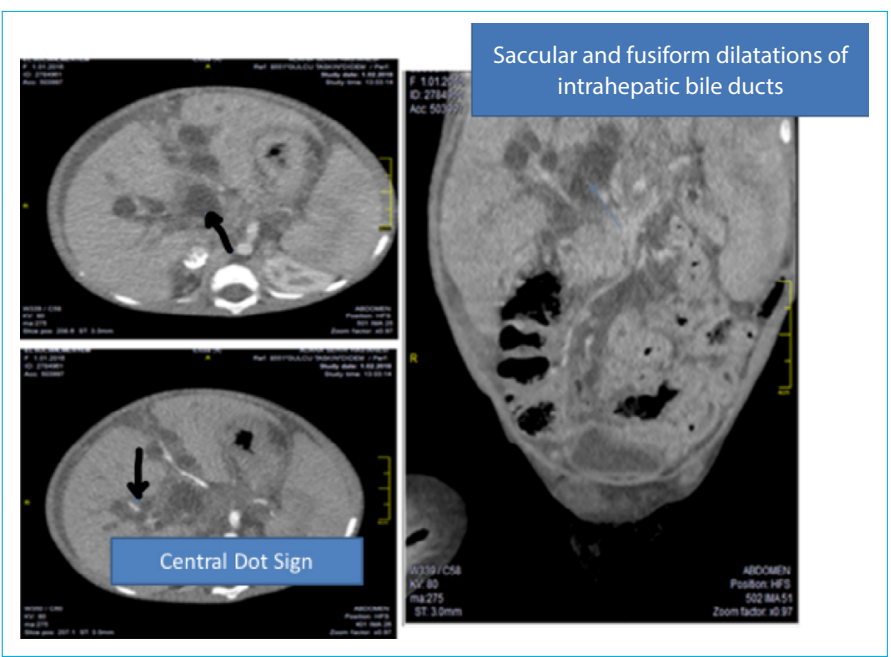

Figure 2. Computed tomography.

Axial and coronal images showed saccular and fusiform dilatations of intrahepatic bile ducts in both liver lobe and a tiny dot with strong contrast enhancement within intrahepatic bile ducts 'Central Dot Sign'.

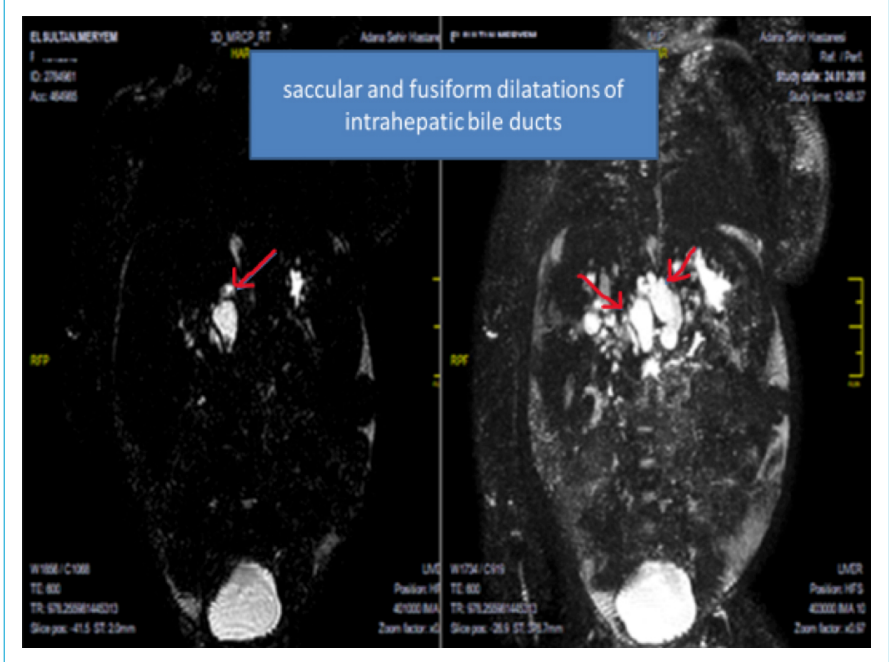

Figure 3. Magnetic Resonance Imaging (axial arterial, portal, venous phase and Coronal T2W FSE sequences) and Magnetic resonance cholangiopancreatography.

Two images showed saccular biliary dilatation of the intrahepatic biliary tree on both liver lobes. The choledochal duct measurement (extrahepatic bile duct) was normal.

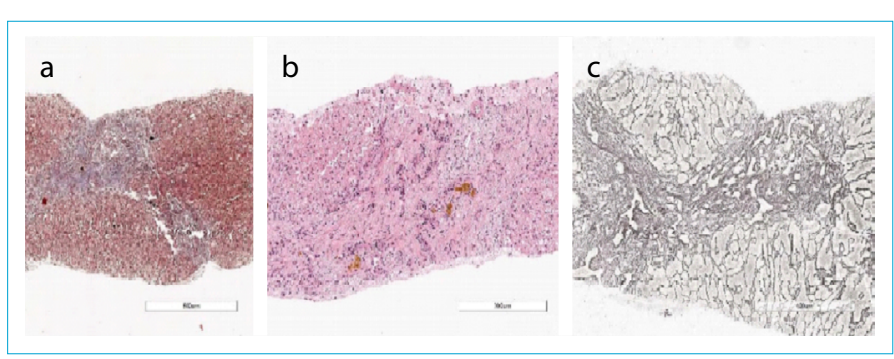

Figure 4. Liver biopsy: (a) Bridging and nodule formation (x25 Trichrome stain), (b) Bile pigment accumulation (x40 Hematoxylin and eosin stain), (c) Cirrhosis (x40 Reticulum stain).

The patient was diagnosed with CS by the evaluation of clinical findings, laboratory findings, liver pathology through biopsy and imaging methods. Due to having cholangitis attacks, blood culture was taken and third generation cephalosporins $(100 \mathrm{mg} / \mathrm{kg} /$ day, divided three doses, intravenous) and metronidazole ( $30 \mathrm{mg} /$ day, divided three dose, intravenous) antibiotherapy treatment was started. Ursodeoxycholic acid and lipid soluble vitamins (5751 IU vitamin A, $400 \mathrm{IU}$ vitamin $\mathrm{D}, 50 \mathrm{IU}$ vitamin $\mathrm{E}$ (plus $15 \mathrm{mg}$ of mixed tocopherols), and $400 \mathrm{mcg}$ vitamin $\mathrm{K}$ (phytonadione) with a combination of water-soluble vitamins, form along with important antioxidants, such as coenzyme Q10, beta-carotene, and gamma Tocopherol) were added to the treatment. On the second day of antibiotherapy, her inflammatory parameters began to improve and her treatment was completed in two weeks and stopped. The patient was included in the transplant list for liver transplantation. The patient's consent was obtained from parents.

\section{DISCUSSION}

CS was first discovered in 1958 by Jacques Carol, a congenital anomaly of the biliary tract with an autosomal recessive trait in most cases, often accompanied by cystic dilatations of the intrahepatic biliary tract and congenital hepatic fibrosis. ${ }^{[6]}$ Although the frequency of $C S$ is higher than $C D$, the prognosis is poor, complications related to portal hypertension and cirrhosis develop early, and treatment should be started as soon as suspected. In $64 \%$ of patients with CS, the main symptom is recurrent cholangitis attacks. ${ }^{[7]}$

The diagnosis is made by clinical, laboratory and radiological findings with liver biopsy. Specifically, in the abdominal tomography, 'Central Dot Sign' is a radiological view formed by the fibrovascular structure containing the portal vein and hepatic artery branches in the cyst, which is a characteristic finding of CS that was also detected in our patient. Although endoscopic retrograde cholangiopancreatography is recommended for the purpose of treatment and in many cases in the literature for the treatment of intrahepatic gallstones and biliary sludge, it was not per- 
formed because of the absence of biliary sludge, stone, and an invasive cause in our patient. ${ }^{[8]}$ In some studies on treatment, it has been shown that in cases where the disease is limited in one lobe, the cure can be achieved with partial lobectomy. ${ }^{[0]}$

The timing of liver transplantation is very important in CS. It should be remembered that the development of cholangiocarcinoma is more common in this patient group than in a healthy population. Liver transplantation should be performed without recurrent attacks of cholangitis and without complications associated with portal hypertension. ${ }^{[10]}$

\section{CONCLUSION}

CS is a rare syndrome with poor prognosis, complications related to portal hypertension and cirrhosis develop early, and treatment should be started as soon as suspected. It is very significant to refer the patient to the liver transplantation center before complications develop. CS should be considered in the differential diagnosis in every patient presenting with cholestasis, especially in the presence of recurrent cholangitis attacks.

\section{Disclosures}

Conflict of Interest: None.

Peer-review: Externally peer-reviewed.

Financial Disclosure: None.

Authorship contributions: Concept - D.G.T.; Design- S.S.; Supervision - G.T.; Materials - D.G.T.; Data collection \&/or processing - S.Y.; Analysis and/or interpretation - A.S.K.; Literature search E.A.; Writing - D.G.T.; Critical Review - G.T.

\section{REFERENCES}

1. Desmet VJ. Congenital diseases of intrahepatic bile ducts: variations on the theme "ductal plate malformation". Hepatology 1992;16(4):1069-83. [CrossRef]

2. Giovanardi RO. Monolobar Caroli's disease in an adult. Case report. Hepatogastroenterology 2003;50(54):2185-87.

3. Lu SC, Debian KA. Cystic diseases of the biliary tract. Textbook of gastroenterology. Philadelphia: Lippincott Williams and Wilkins; 2003. p. 2225-33.

4. Sato Y, Ren XS, Nakanuma Y. Caroli's disease: current knowledge of its biliary pathogenesis obtained from an orthologous rat model. Int J Hepatol 2012:107945. [CrossRef]

5. Hwang MJ, Kim TN. Diffuse-type Caroli disease with characteristic central dot sign complicated by multiple intrahepatic and common bile duct stones. Clin Endosc 2017;50(4):400-3.

6. Caroli J, Couinaud C, Soupault R, Porcher P, Eteve J. A new disease,undoubtedly congenital, of the bile ducts: unilobar cystic dilation ofthe hepatic ducts. Sem Hop 1958;34:496502.

7. Yonem O, Bayraktar Y. Clinical characiteristics of Caroli's syndrome. World J Gastroenterol 2007;13(13):1934-7. [CrossRef]

8. Taş Ş, Atıcı AE, Duman M, Ekiz F, Aydın MF, Özer İ, et all. Caroli hastalığı: olgu sunumu. Cumhuriyet Tıp Derg 2010;32:241-6.

9. Bockhorn M, Malagó M, Lang H, Nadalin S, Paul A, Saner F, et al. The role of surgery in Caroli's disease. J Am Coll Surg 2006;202(6):928-32. [CrossRef]

10. Harring TR, Nguyen NT, Liu H, Goss JA, O'Mahony CA. Caroli disease patients have excellent survival after liver transplant. J Surg Res 2012;177(2):365-72. [CrossRef] 